\title{
Human Bocavirus Infection in Adults: Clinical Features and Radiological Findings
}

\author{
Han Na Lee, MD, PhD ${ }^{1}$, Hyun Jung Koo, MD, PhD², Soo Hyun Kim, MD², Sang-Ho Choi, MD, PhD ${ }^{3}$, \\ Heungsup Sung, MD, PhD ${ }^{4}$, Kyung-Hyun Do, MD, PhD² \\ ${ }^{1}$ Department of Radiology, Kyung Hee University Hospital at Gangdong, College of Medicine, Kyung Hee University, Seoul, Korea; ${ }^{2}$ Department of \\ Radiology and Research Institute of Radiology, Asan Medical Center, University of Ulsan College of Medicine, Seoul, Korea; Departments of \\ ${ }^{3}$ Infectious Diseases and 4 Laboratory Medicine, Asan Medical Center, University of Ulsan College of Medicine, Seoul, Korea
}

Objective: Human bocavirus ( $\mathrm{HBoV}$ ) is a newly identified pathogen that can cause upper and lower respiratory infections usually in children; however, its clinical characteristics and significance in respiratory infections in adults have not been well known. Our objective was to evaluate the clinical features of respiratory HBoV infection and to describe the CT findings of HBoV pneumonia in adults.

Materials and Methods: A total of 185 adult patients diagnosed with HBoV infection at a tertiary referral center between January 2010 and December 2017 were retrospectively evaluated with respect to the clinical characteristics of HBoV infection and its risk factors for pneumonia. Chest CT findings for 34 patients with HBoV pneumonia without co-infection were analyzed and compared between immunocompetent $(n=18)$ and immunocompromised $(n=16)$ patients.

Results: HBoV infections were predominantly noted between February and June. Among the 185 patients with HBoV infection, $119(64.3 \%)$ had community-acquired infections and 110 (59.5\%) had pneumonia. In multivariable analysis, older age (odds ratio [OR], 1.02; 95\% confidence interval [CI], 1.00-1.04; $p=0.045)$ and nosocomial infection (OR, 2.07; 95\% CI, 1.05-4.10; $p=0.037)$ were associated with HBoV pneumonia. The main CT findings were bilateral consolidation (70.6\%) and/or groundglass opacities $(64.7 \%)$; centrilobular nodules $(14.7 \%)$ were found less frequently. The pattern of CT findings were not significantly different between immunocompetent and immunocompromised patients (all, $p>0.05$ ).

Conclusion: $\mathrm{HBoV}$ infection can be a potential respiratory tract infection in adults. The most frequent $\mathrm{CT}$ findings of $\mathrm{HBoV}$ pneumonia were bilateral consolidation and/or ground-glass opacities.

Keywords: Human bocavirus; Pneumonia; Computed tomography

\section{INTRODUCTION}

Human bocavirus ( $\mathrm{HBoV}$ ) is a recently-discovered DNA virus of the Parvoviridae family. Since its first report in 2005, HBoV has been known to cause acute respiratory infections in children (1-6). The clinical manifestations of

Received September 9, 2018; accepted after revision April 7, 2019. Corresponding author: Kyung-Hyun Do, MD, PhD, Department of Radiology and Research Institute of Radiology, Asan Medical Center, University of Ulsan College of Medicine, 88 Olympic-ro 43gil, Songpa-gu, Seoul 05505, Korea.

- Tel: (822) 3010-4352 • Fax: (822) 476-6645

- E-mail: dokh@amc.seoul.kr

This is an 0pen Access article distributed under the terms of the Creative Commons Attribution Non-Commercial License (https://creativecommons.org/licenses/by-nc/4.0) which permits unrestricted non-commercial use, distribution, and reproduction in any medium, provided the original work is properly cited.
$\mathrm{HBoV}$ infection are diverse, ranging from a mild common cold to bronchopneumonia or asthma exacerbation and severe respiratory tract infection (7).

$\mathrm{HBoV}$ has been frequently co-detected with other respiratory viruses or respiratory pathogens in $40-75 \%$ of patients $(2,5,8)$. This viral co-detection has started a debate about the role of $\mathrm{HBOV}$ as a true respiratory pathogen, but emerging evidence has supported the pathogenicity of $\mathrm{HBoV}$. The presence of $\mathrm{HBoV}$ is rare in asymptomatic patients, and specifically, HBoV infections without other detected pathogens have been found in patients with respiratory tract symptoms. In addition, high viral loads have been associated with severe lower respiratory tract infections $(1,9,10)$. In a recent prospective study, $\mathrm{HBoV}$ was the fourth most common pathogen in hospitalized children with respiratory tract 
diseases, with an incidence of $9.9 \%$ (8).

However, HBoV has been rarely detected in adults. According to a previous epidemiology study of respiratory viruses that have been detected in bronchoalveolar lavage (BAL), the incidence of $\mathrm{HBoV}$ infection was $3 \%$ followed by that of human metapneumovirus (4.2\%) (11). Previous studies, mostly case reports (12-14), have shown that HBoV can cause severe pneumonia in immunocompromised adults or elderly patients; however, the clinical characteristics and burden of HBoV infection in adults have not been thoroughly elucidated.

As with other infections, chest computed tomography (CT) scans can show the pattern and extent of viral pneumonia, and $\mathrm{CT}$ findings of viral pneumonia tend to show similar patterns according to viral pathogen viridae, with partial overlap $(7,15)$. However, for this approach, the CT findings of pneumonia need to be evaluated with respect to the etiology of each virus. To our knowledge, the CT findings of HBoV pneumonia have only been reported in one case report (13). Therefore, the purpose of this study was to describe the clinical characteristics of HBoV infections and the $\mathrm{CT}$ findings of $\mathrm{HBoV}$ pneumonia in adults using a large population cohort of a tertiary hospital.

\section{MATERIALS AND METHODS}

\section{Data Collection}

This retrospective cohort study was conducted with the approval of the Institutional Review Board at the Asan Medical Center (approval number: 2018-0009), and the requirement for informed consent was waived. A total of 185 patients who had laboratory-confirmed HBoV infection between January 2010 and December 2017 were identified by retrospective data search. Nasopharyngeal samples were collected when patients had symptoms of acute respiratory infection. BAL was performed if there was no definite pathogen identified from nasopharyngeal swab, even though pneumonia was suspected with abnormal chest radiography or CT findings. A reverse-transcription polymerase chain reaction assay was performed to detect respiratory viruses in nasopharyngeal secretions and or BAL fluid using a Seeplex ${ }^{\circledR}$ RV 15 ACE Detection kit or Anyplex ${ }^{\text {TM }}$ II RV 16 Detection kit (Seegene Inc., Seoul, Korea). The laboratory threshold amplification product was 200 relative fluorescence units for detection of $\mathrm{HBoV}$. Patient characteristics including demographics, smoking history, underlying chronic disease, body mass index, immune status, and features of HBoV infection, which included seasonality, type of infection (community acquired or nosocomial), and presence of co-infection were reviewed. We also studied laboratory findings and clinical outcomes which included emergency room visits, requirement for hospitalization, intensive care unit admission, and all-cause mortality rate (30 days, 90 days, and overall mortality from the initial diagnosis of $\mathrm{HBoV}$ infection).

\section{Definitions}

Upper respiratory infection (URI) was defined as positive $\mathrm{HBOV}$ in nasopharyngeal samples from patients with URI symptoms, such as cough, sputum, and rhinorrhea. Pneumonia was defined as the detection of $\mathrm{HBoV}$ in nasopharyngeal samples or BAL, with initial or new pulmonary opacities on chest radiography or CT images. Patients diagnosed with pneumonia two days after the initial URI diagnosis were considered to progress from URI to pneumonia. Immunocompromised patients were defined according to a previous study (16). Community-acquired infection was considered when patients developed acute respiratory symptoms while they were outside the hospital or within the first five days after admission (17). Coinfection was defined as the detection of other potential respiratory pathogens in nasopharyngeal samples, BAL, sputum, or blood cultures within 15 days before and after the HBoV infection. Neutropenia was defined as an absolute neutrophil count $<1000 / \mathrm{mL}$, and lymphopenia was defined as an absolute lymphocyte count $<500 / \mathrm{mL}$ (18).

\section{СT Acquisition}

$\mathrm{CT}$ was performed in the patients with $\mathrm{HBoV}$ pneumonia with more severe clinical course. A total of $34 \mathrm{CT}$ examinations obtained within 2 weeks after the diagnosis of HBoV pneumonia without co-infection were reviewed. CT examinations were performed on 16- or 64-detector CT scanners (SOMATOM Sensation 16, Siemens Healthcare, Forchheim, Germany; and LightSpeed VCT, GE Healthcare, Milwaukee, WI, USA). The 16-detector row CT used 120 $k V p, 100$ effective $\mathrm{mAs}$ with dose modulation, and a tube rotation time of $0.5 \mathrm{~ms}$. The 64 -detector row CT scanners were set to $120 \mathrm{kVp}$ and $100 \mathrm{mAs}$ to $400 \mathrm{mAs}$ with dose modulation. All reconstructions were done at $2.5 \mathrm{mAs}$ or $3 \mathrm{~mm} / 5 \mathrm{~mm}$ thickness reconstruction intervals without a gap using the standard algorithm, and $1 \mathrm{~mm}$ or $1.25 \mathrm{~mm}$ thicknesses with $5 \mathrm{~mm}$ gaps using the high-frequency algorithm. Intravenous contrast agent was used in 17 of 34 
patients. For enhanced chest $\mathrm{CT}$, images were obtained after intravenous injection of $100 \mathrm{~mL}$ iopromide $300(300 \mathrm{mg}$ iodine $/ \mathrm{mL}$ ) (Ultravist ${ }^{\circledR}$; Bayer $\mathrm{AG}$, Berlin, Germany) at a rate of $2.5 \mathrm{~mL} / \mathrm{s}$ by using a power injector.

\section{Analysis of CT Findings}

CT findings were reviewed in consensus by two chest radiologists (with 4 years of experience in chest imaging). Patterns of parenchymal abnormalities were assessed for the presence of consolidation, ground-glass opacity (GG0), centrilobular nodules, macronodules, cavities, and interlobular septal and/or intralobular interstitial thickening. In addition, the presence of lymphadenopathy (hilar/mediastinal), and pleural effusion was recorded. CT patterns were defined based on the glossary of terms provided by the Fleishner Society (19) and macronodules were defined as nodules more than $1.0 \mathrm{~cm}$ in diameter (20). With respect to the extent of parenchymal abnormalities, the total extent and the extent of each consolidation and GG0 were assessed using a percent volumetric scale. The total number of involved lobes was also evaluated. The distribution of parenchymal abnormalities was evaluated for bilaterality and axial (central, peripheral, mixed), and longitudinal (upper, lower, mixed) locations. The inner twothirds of the lung was defined as central and the outer third of the lung was defined as peripheral with respect to axial location. The lesions above the hilum were regarded as upper and those below the hilum were regarded as lower with respect to longitudinal distribution. The lesions that involved the lung parenchyma without dominant distribution were considered to have mixed distributions. Finally we divided the CT patterns of pneumonia into airway centric, multifocal pneumonia, focal pneumonia and diffuse pneumonia provided by Miller et al. (21). All axial and coronal CT images were reviewed on the picture archiving and communication system using lung (window width 1500 Hounsfield unit [HU], window level $-700 \mathrm{HU}$ ) and mediastinal (window width $450 \mathrm{HU}$, window level $50 \mathrm{HU}$ ) windows for reading.

\section{Statistical Analysis}

Clinical and $\mathrm{CT}$ findings of $\mathrm{HBoV}$ infections were compared for categorical variables using the chi-square test or Fisher's exact test and for continuous variables using the independent $t$ test. Multivariable logistic regression was performed to identify cross-sectional associations between each risk factor and pneumonia occurrence among all patients. All variables with $p$ values less than 0.1 in univariate analysis were entered into the multivariate analysis and the results were shown as odds ratios (0Rs) and $95 \%$ confidence intervals (CIs). $P$ values less than 0.05 were considered to be significant. All statistical calculations were performed using SPSS version 21.0 (IBM Corp., Armonk, NY, USA).

\section{RESULTS}

\section{Patient Characteristics and Seasonality of HBoV Infection}

A total of 185 patients were identified with laboratoryconfirmed HBoV infection; 75 (40.5\%) and 110 (59.5\%) had URI alone and pneumonia, respectively. Patient characteristics are shown in Table 1 . The mean age was 57 \pm 19 years (range, $17-98$ years), and $41.1 \%$ of the patients were over 65 years of age. Among the 185 patients, 76 (41.1\%) patients were immunocompromised; 28 (36.8\%) had solid tumors that were treated with chemotherapy within 6 months, since diagnosis of HBoV infection, 11 $(14.5 \%)$ had hematologic malignancies, $19(25.0 \%)$ had solid organ transplantations, and $18(23.7 \%)$ received hematopoietic cell transplantation. One hundred nineteen $(64.3 \%)$ patients had community-acquired infections, and co-infections were detected in 88 patients $(47.6 \%)$ (Supplementary Table 1). The most frequent respiratory viral co-pathogens were rhinovirus $(n=8,10.7 \%)$ in URI and adenovirus $(n=5,4.6 \%)$ and influenza $A$ or $B$ virus $(n=5$, $4.6 \%$ ) in pneumonia. The monthly and year distributions of all patients with $\mathrm{HBoV}$ infections between January 2010 and December 2017 are shown in Figure 1. HBoV infection was predominantly noted from February to June, with a peak incidence in April (15.7\%) (Fig. 1A). When the incidence of $\mathrm{HBoV}$ infections increased, pneumonia occurred more frequently, and this incidence has increased by approximately three times since 2014, compared to that before this period (Fig. 1B).

\section{Clinical Outcomes of HBoV Infection}

Seventy-three patients (39.5\%) visited the emergency department because of a HBoV infection. Among the 80 patients who visited the emergency department or the outpatient clinic, 46 patients $(57.5 \%)$ were admitted to the hospital with secondary to infections. Seven patients (3.8\%) required intensive care unit care with intubation. All-cause mortality rates at 30 and 90 days from diagnosis of $\mathrm{HBoV}$ 
Table 1. Patient Characteristics and Clinical Outcomes of HBoV Infection

\begin{tabular}{|c|c|c|c|c|}
\hline Characteristics & Total $(n=185)$ & URI $(n=75)$ & Pneumonia $(n=110)$ & $P$ \\
\hline Age & $57 \pm 19$ & $53 \pm 19$ & $59 \pm 18$ & 0.033 \\
\hline Male & $115(62.2)$ & $41(54.7)$ & $74(67.3)$ & 0.083 \\
\hline Smoking & & & & 0.132 \\
\hline Never smoker & $120(64.9)$ & $48(64.0)$ & $72(65.5)$ & \\
\hline Former smoker & $24(20.5)$ & $16(21.3)$ & $22(20.0)$ & \\
\hline Current smoker & $24(13.0)$ & $9(12.0)$ & $15(13.6)$ & \\
\hline Chronic disease & $72(38.9)$ & $26(34.7)$ & $46(41.8)$ & 0.959 \\
\hline DM & $43(23.2)$ & $14(18.7)$ & $29(26.4)$ & \\
\hline COPD & $16(8.6)$ & $4(5.3)$ & $12(10.9)$ & \\
\hline CKD & $5(2.7)$ & $3(4.0)$ & $2(1.8)$ & \\
\hline Others & $21(11.4)$ & $8(10.7)$ & $13(11.8)$ & \\
\hline Immune status & & & & 0.805 \\
\hline Immunocompetent & $109(58.9)$ & $45(60.0)$ & $64(58.2)$ & \\
\hline Immunocompromised & $76(41.1)$ & $30(40.0)$ & $46(41.8)$ & \\
\hline Body mass index, $\mathrm{kg} / \mathrm{m}^{2}$ & $22.6 \pm 4.3$ & $23.2 \pm 3.5$ & $22.2 \pm 4.8$ & 0.130 \\
\hline Type of infection & & & & 0.035 \\
\hline Community-acquired & $119(64.3)$ & $55(73.3)$ & $64(58.2)$ & \\
\hline Nosocomial & $66(35.7)$ & $20(26.7)$ & $46(41.8)$ & \\
\hline Co-infection & & & & 0.615 \\
\hline None & $97(52.4)$ & $41(54.7)$ & $56(50.9)$ & \\
\hline Yes & $88(47.6)$ & $34(45.3)$ & $54(49.1)$ & \\
\hline Emergency room visit & $73(39.5)$ & $28(37.3)$ & $45(40.9)$ & 0.239 \\
\hline Admission secondary to infection* & $46 / 80(57.5)$ & $12 / 34(35.3)$ & $34 / 46(73.9)$ & 0.001 \\
\hline ICU admission & $7(3.8)$ & $2(2.7)$ & $5(4.5)$ & 0.703 \\
\hline All-cause mortality, $30 \mathrm{~d}^{\dagger}$ & $14(7.6)$ & $4(5.3)$ & $10(9.1)$ & 0.343 \\
\hline All-cause mortality, $90 \mathrm{~d}^{\dagger}$ & $24(13.0)$ & $6(8.0)$ & $18(16.4)$ & 0.096 \\
\hline Overall mortality $^{\dagger}$ & $39(21.1)$ & $10(13.3)$ & $29(26.4)$ & 0.033 \\
\hline Neutrophil count & & & & 1.000 \\
\hline$>1.0 \times 10^{3} / \mu \mathrm{L}$ & $171(93.4)$ & $69(92.0)$ & $102(92.7)$ & \\
\hline$\leq 1.0 \times 10^{3} / \mu \mathrm{L}$ & $12(6.6)$ & $5(6.7)$ & $7(6.4)$ & \\
\hline Lymphocyte count & & & & 0.084 \\
\hline$>0.5 \times 10^{3} / \mu \mathrm{L}$ & $147(92.4)$ & $64(86.5)$ & $83(76.1)$ & \\
\hline$\leq 0.5 \times 10^{3} / \mu \mathrm{L}$ & $36(9.7)$ & $10(13.5)$ & $26(23.9)$ & \\
\hline Steroid use & & & & 0.878 \\
\hline None & $142(76.8)$ & $58(77.3)$ & $84(76.4)$ & \\
\hline Yes & $43(23.2)$ & $17(22.7)$ & $26(23.6)$ & \\
\hline
\end{tabular}

Data are indicated as number and percentages in parenthesis or means \pm standard deviation unless specified otherwise. ${ }^{*}$ This analysis was restricted to outpatients or patients who visited emergency room, 'Specific mortality rates at 30 days, 90 days and overall for HBoV infection without co-infection were $5.2 \%, 9.3 \%$, and $20.6 \%$, respectively. CKD = chronic kidney disease, COPD = chronic obstructive pulmonary disease, $\mathrm{d}=$ day, $\mathrm{DM}=$ diabetes mellitus, $\mathrm{HBOV}=$ human bocavirus, $\mathrm{ICU}=$ intensive care unit, URI = upper respiratory infection

infection were $7.6 \%$ and $13.0 \%$, and the overall mortality rate was $21.1 \%$. As for $\mathrm{HBoV}$ infection without co-infection, all-cause mortality rates at 30 and 90 days were $5.2 \%$ and $9.3 \%$ and the overall mortality rate was $20.6 \%$.

Among the 83 patients who initially presented with URI, eight $(9.6 \%)$ patients progressed from URI to pneumonia after a median of 3.5 days (range, 2-13 days). In a multivariable logistic regression among all patients, older age (OR, 1.02; CI, $1.00-1.04 ; p=0.045)$ and nosocomial infection (OR, 2.07; CI, 1.05-4.10; $p=0.037$ ) were significant factors associated with pneumonia (Table 2).

\section{CT Findings of HBoV Pneumonia}

Among the 110 patients who had HBoV pneumonia, 56 had HBoV pneumonia without co-infection and CT findings were analyzed in 34 patients (immunocompetent: 


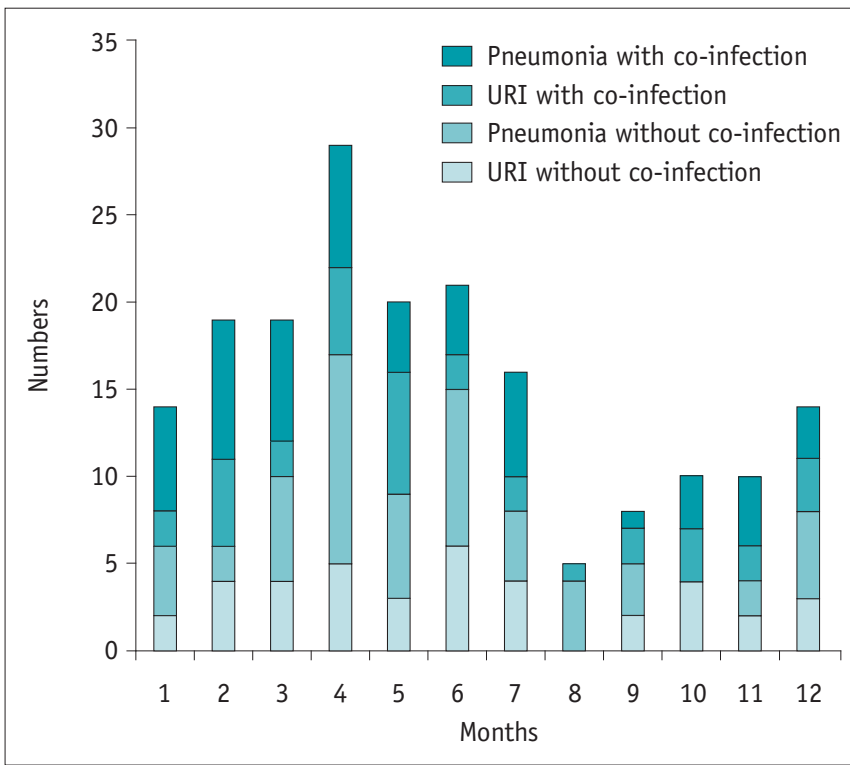

Fig. 1. Monthly and yearly distributions of HBoV infections from January 2010 and December 2017.

Number of patients with HBoV infections among 185 patients are shown by month (A) and by year (B) according to respiratory site and presence of co-pathogens. HBoV = human bocavirus, URI = upper respiratory infection

Table 2. Clinical Factors Associated with HBoV Pneumonia

\begin{tabular}{|c|c|c|c|c|c|c|}
\hline \multirow{2}{*}{ Characteristics } & \multicolumn{3}{|c|}{ Univariate Analysis } & \multicolumn{3}{|c|}{ Multivariate Analysis } \\
\hline & OR & $95 \% \mathrm{CI}$ & $P$ & OR & $95 \% \mathrm{CI}$ & $P$ \\
\hline Age & 1.02 & $1.00-1.03$ & 0.034 & 1.02 & $1.00-1.04$ & 0.045 \\
\hline \multicolumn{7}{|l|}{ Sex } \\
\hline Male & 1.00 & & & 1.00 & & \\
\hline Female & 0.59 & $0.32-1.07$ & 0.084 & 0.57 & $0.30-1.09$ & 0.090 \\
\hline \multicolumn{7}{|l|}{ Smoking } \\
\hline Never smoker & 1.00 & & & & & \\
\hline Former/current smoker & 0.99 & $0.53-1.84$ & 0.966 & & & \\
\hline \multicolumn{7}{|l|}{ Underlying chronic disease } \\
\hline No & 1.00 & & & & & \\
\hline Yes & 1.36 & $0.74-2.49$ & 0.333 & & & \\
\hline \multicolumn{7}{|l|}{ Neutropenia } \\
\hline No & 1.00 & & & & & \\
\hline Yes & 0.95 & $0.29-3.11$ & 0.928 & & & \\
\hline \multicolumn{7}{|l|}{ Lymphopenia } \\
\hline No & 1.00 & & & 1.00 & & \\
\hline Yes & 2.01 & $0.90-4.46$ & 0.099 & 1.80 & $0.78-4.14$ & 0.170 \\
\hline \multicolumn{7}{|l|}{ Type of infection } \\
\hline Community-acquired & 1.00 & & & 1.00 & & \\
\hline Nosocomial & 1.98 & $1.05-3.74$ & 0.044 & 2.07 & $1.05-4.10$ & 0.037 \\
\hline \multicolumn{7}{|l|}{ Steroids } \\
\hline None & 1.00 & & & & & \\
\hline Yes & 1.06 & $0.53-2.10$ & 0.888 & & & \\
\hline \multicolumn{7}{|l|}{ Co-infection } \\
\hline None & 1.00 & & & & & \\
\hline Yes & 1.16 & $0.65-2.10$ & 0.622 & & & \\
\hline Body mass index, $\mathrm{kg} / \mathrm{m}^{2}$ & 0.944 & $0.87-1.02$ & 0.142 & & & \\
\hline
\end{tabular}

$\mathrm{CI}=$ confidence interval, $\mathrm{OR}=$ odds ratio 
immunocompromised $=18: 16$ ) who performed chest $C T$ within 2 weeks of $\mathrm{HBoV}$ detection (Fig. 2). They had performed chest $\mathrm{CT}$ within an average $2.2 \pm 3.6$ days from the initial diagnosis.

The patterns and distributions of $\mathrm{CT}$ findings are described in Table 3. The most frequent CT findings were consolidation $(n=24,70.6 \%)$ and GGO $(n=22,64.7 \%)$ followed by interlobular and/or intralobular septal thickening $(n=$ $14,41.2 \%)$, bronchial wall thickening $(n=13,38.2 \%)$, centrilobular nodules $(n=5,14.7 \%)$ and macronodules $(\mathrm{n}=3,8.8 \%)$. Cavities were not observed in any patient. Mediastinal and/or hilar lymph node enlargement was found in $10(29.4 \%)$ patients and pleural effusion was observed in $17(50.0 \%)$ patients.

Parenchymal abnormalities were found bilaterally in 19 $(55.9 \%)$ patients. The predominant axial distributions were mixed in $23(67.6 \%)$ patients and peripheral in $9(26.5 \%)$ patients. Predominant longitudinal locations were mixed in $18(52.9 \%)$ patients followed by lower lung zone in 10 (29.4\%) patients.

The average number of involved lobes and percent extent of the involved area of the lung were $3.4 \pm 2.1$ and $27.5 \pm$ $25.2 \%$, respectively. The most frequent pneumonia type was multifocal pneumonia $(n=12,35.3 \%)$, followed by airway centric $(n=10,29.4 \%)$, focal pneumonia $(n=8,23.5 \%)$ and diffuse pneumonia $(n=4,11.8 \%)$.

\section{CT Findings according to Immune Status}

The most frequent CT finding both in immunocompetent and immunocompromised patients was bilateral

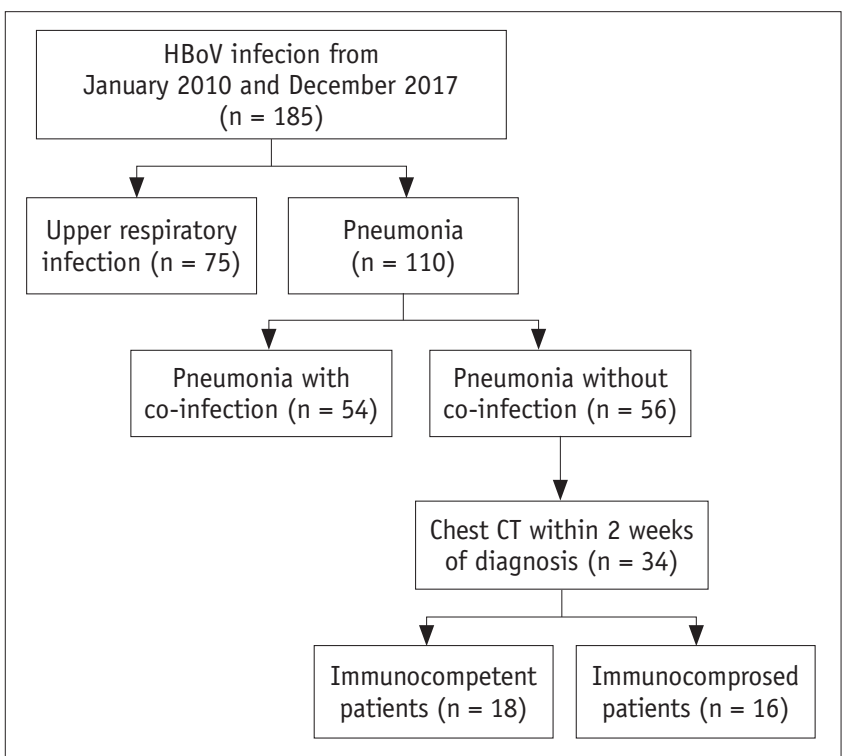

Fig. 2. Flow diagram of patient selection with HBoV infection. consolidation and/or GGO without axial and longitudinal zonal predominance. There was no significant difference in CT patterns and distributions between the two groups (all, $p>0.05$ ). Although the disease extent (total and each for consolidation and GG0) was larger in immunocompromised patients than in immunocompetent patients, differences were not statistically significant. The most frequent pneumonia type was airway centric for immunocompetent patients (Fig. 3) and multifocal pneumonia for immunocompromised patients (Fig. 4).

\section{DISCUSSION}

In this study we showed that $\mathrm{HBoV}$ can cause respiratory infection in adults and older age and nosocomial infection were associated with $\mathrm{HBoV}$ pneumonia. The predominant $\mathrm{CT}$ findings of $\mathrm{HBOV}$ pneumonia were bilateral consolidation and/or GG0 without zonal predominance with multifocal pneumonia pattern. The CT findings were not significantly different between immunocompetent and immunocompromised patients.

$\mathrm{HBOV}$ is a newly detected pathogen that can cause acute respiratory infection (6). Most studies have focused on HBoV infection in infants and young children $(2,4,8)$, possibly due to its higher incidence in those populations than in adults (12). Moreover, most cases of HBoV infection in adults have been reported in immunocompromised patients $(1,12,13)$. In this study, $58.9 \%$ of all patients with $\mathrm{HBoV}$ infection were immunocompetent showing that immunocompetent adults can also be infected with $\mathrm{HBoV}$. We suspect that an increase in the frequency of prescription and technical improvements in viral detection tests, such as reverse-transcription polymerase chain reaction assays, may contribute to an increase in HBoV infection diagnoses.

In our study, $52.4 \%$ of patients showed HBoV infection without co-infection, which indicates that $\mathrm{HBoV}$ is a real etiological pathogen in adults. However, HBoV has also been frequently found with other respiratory pathogens, and the role of HBoV infection among co-pathogens has not been determined (14). Previous studies have demonstrated that high viral loads were significantly noted in patients with $\mathrm{HBoV}$ infection without co-infection, compared to patients with $\mathrm{HBoV}$ and co-pathogen infections, which suggests that high viral loads are indicative of a causative role for $\operatorname{HBoV}(2,22,23)$. Further studies are needed to determine whether HBoV among co-detected pathogens acts as a causative or exacerbating factor or whether our 
Table 3. СT Findings of HBoV Pneumonia without Co-Infection according to Immune Status

\begin{tabular}{|c|c|c|c|c|}
\hline CT Findings & $\begin{array}{c}\text { Total } \\
(n=34)\end{array}$ & $\begin{array}{l}\text { Immunocompetent } \\
(n=18)\end{array}$ & $\begin{array}{l}\text { Immunocompromised } \\
\qquad(\mathrm{n}=16)\end{array}$ & $P$ \\
\hline Consolidation & $24(70.6)$ & $12(66.7)$ & $12(75.0)$ & 0.715 \\
\hline GG0 & $22(64.7)$ & $11(61.1)$ & $11(68.8)$ & 0.642 \\
\hline Centrilobular nodules & $5(14.7)$ & $3(16.7)$ & $2(12.5)$ & 1.000 \\
\hline Macronodules $(>1.0 \mathrm{~cm})$ & $3(8.8)$ & $1(5.6)$ & $2(12.5)$ & 0.591 \\
\hline Interlobular and intralobular septal thickening & $14(41.2)$ & $8(44.4)$ & $6(37.5)$ & 0.681 \\
\hline Bronchial wall thickening & $13(38.2)$ & $8(44.4)$ & $5(31.3)$ & 0.429 \\
\hline Lymphadenopathy & $10(29.4)$ & $7(38.9)$ & $3(18.8)$ & 0.270 \\
\hline Hilar & 5 & 3 & 2 & \\
\hline Mediastinal & 1 & 1 & 0 & \\
\hline Hilar and mediastinal & 4 & 3 & 1 & \\
\hline Pleural effusion & $17(50.0)$ & $7(38.9)$ & $10(62.5)$ & 0.169 \\
\hline No. of involved lobes & $3.4 \pm 2.1$ & $3.3 \pm 2.0$ & $3.4 \pm 2.2$ & 0.886 \\
\hline Total extent of involved lobes (\%) & $27.5 \pm 25.2$ & $21.7 \pm 22.6$ & $34.0 \pm 27.0$ & 0.157 \\
\hline Consolidation extent (\%) & $13.4 \pm 15.9$ & $10.6 \pm 13.4$ & $16.6 \pm 18.2$ & 0.273 \\
\hline GG0 extent (\%) & $10.3 \pm 17.7$ & $10.3 \pm 19.6$ & $10.4 \pm 15.9$ & 0.988 \\
\hline Bilaterality & $19(55.9)$ & $11(61.1)$ & $8(50.0)$ & 0.515 \\
\hline Axial location & & & & 0.360 \\
\hline Central & $2(5.9)$ & $2(11.1)$ & $0(0.0)$ & \\
\hline Peripheral & $9(26.5)$ & $5(27.8)$ & $4(25.0)$ & \\
\hline Mixed & $23(67.6)$ & $11(61.1)$ & $12(75.0)$ & \\
\hline Longitudinal location & & & & 0.759 \\
\hline Upper & $6(17.6)$ & $4(22.2)$ & $2(12.5)$ & \\
\hline Lower & $10(29.4)$ & $5(27.8)$ & $5(31.3)$ & \\
\hline Mixed & $18(52.9)$ & $9(50.0)$ & $9(56.3)$ & \\
\hline Pneumonia type & & & & 0.275 \\
\hline Airway centric & $10(29.4)$ & $8(44.4)$ & $2(12.5)$ & \\
\hline Multifocal pneumonia & $12(35.3)$ & $4(22.2)$ & $8(50.0)$ & \\
\hline Focal pneumonia & $8(23.5)$ & $4(22.2)$ & $4(25.0)$ & \\
\hline Diffuse pneumonia & $4(11.8)$ & $2(11.1)$ & $2(12.5)$ & \\
\hline
\end{tabular}

Data demonstrated mean \pm standard deviation or number and percentages in parenthesis. GG0 = ground-glass opacity

findings result from the long-term shedding of HBoV DNA.

An overall pneumonia rate of $59.5 \%$ was observed in this study. This is higher than that observed by previous studies, which reported a pneumonia rate of $29.2 \%$ in a pediatric cohort with HBoV infection (14) and a pneumonia rate of $25-49.2 \%$ in patients with human metapneumovirus (17, 24, 25).

Previously, one case report has described the CT findings of $\mathrm{HBoV}$ pneumonia as reticulonodular opacities predominantly in both lower lobes (13). Although HBoV pneumonia showed various $\mathrm{CT}$ features and it was difficult to describe specific findings, the $\mathrm{HBoV}$ pneumonia predominantly showed bilateral areas of consolidation (70.6\%) and/or GG0 (64.7\%), whereas airway inflammatory findings such as bronchial wall thickening (38.2\%) and centrilobular nodules (14.7\%) were less frequently observed. When viral pneumonia is suggested in clinical practice, $\mathrm{HBoV}$ can be considered one of the etiologies, regardless of the patients' immune status, particularly when chest $\mathrm{CT}$ reveals a multifocal pneumonia pattern.

However a multifocal pneumonia pattern can be also seen in other viral pneumonia conditions such as H1N1 influenza, Hanta and adenovirus infection with overlapping CT findings $(21,26,27)$. H1N1 influenza frequently involves the peripheral and lower lung zones and pleural effusion is rare. Hantavirus may cause similar viral pneumonia in immunocompetent adults with respiratory distress with or without rapid progression to airspace consolidation. In addition, adenovirus can cause segmental consolidation and GGO in immunocompromised hosts.

$\mathrm{CT}$ findings of HBoV pneumonia did not significantly differ between patients who were immunocompetent and 


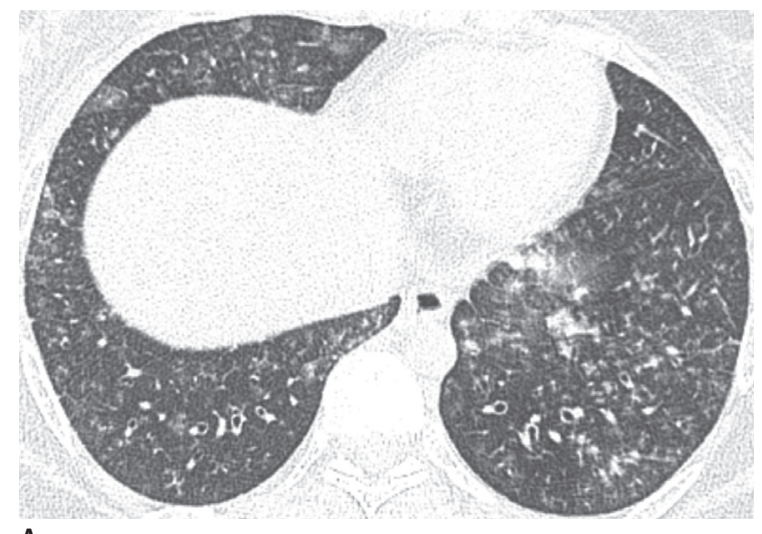

A
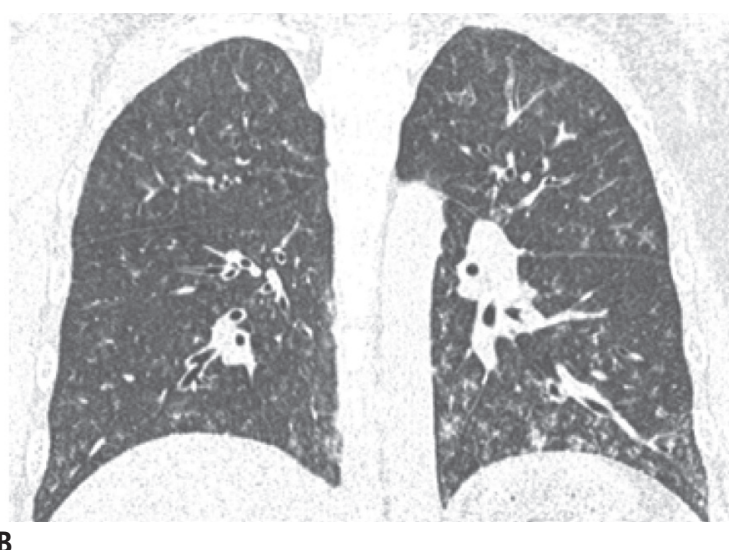

Fig. 3. 30-year-old female without underlying disease was admitted with cough and fever.

A, B. CT showed multiple ill-defined centrilobular nodules with bronchial wall thickening (airway centric pattern) in both lungs. Three days later, lesions had resolved completely (not shown).

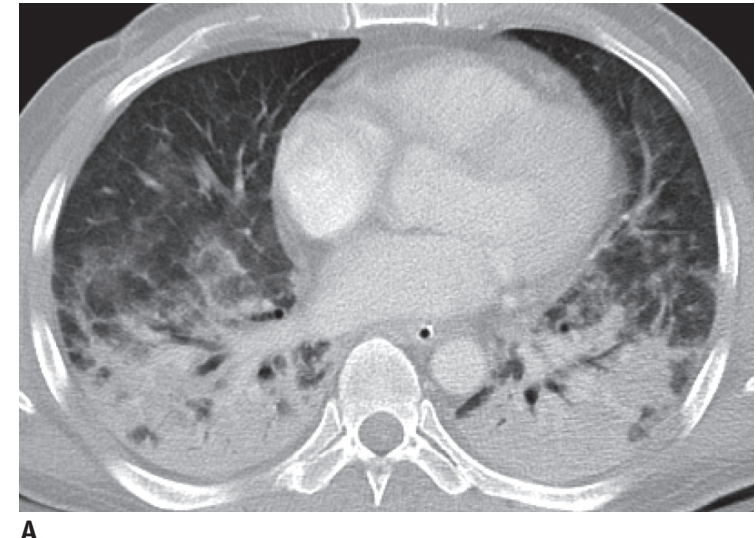

A

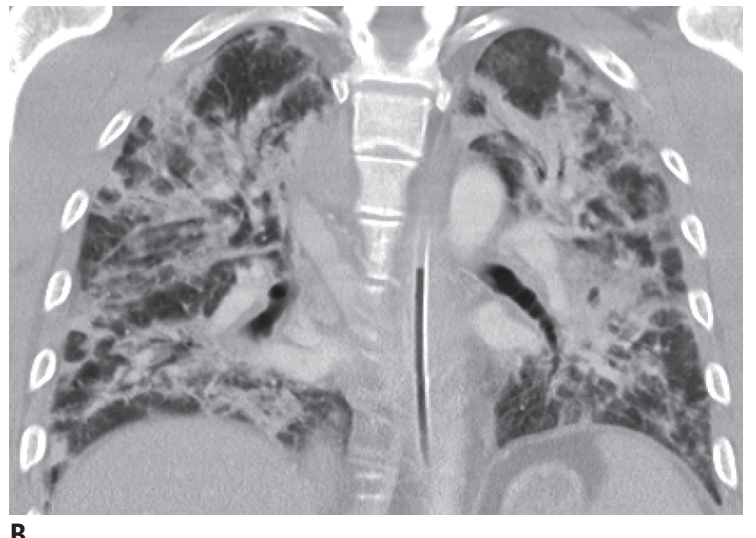

B

Fig. 4. 53-year-old male who had undergone liver transplantation eight months earlier presented with fever at emergency department.

A, B. Bilateral ground glass opacities and peribronchial consolidations (multifocal pneumonia pattern) without pleural effusion were shown on CT images. He was admitted to intensive care unit, and intubated (not shown). Three weeks after initial presentation, HBoV pneumonia was improved, and patient was discharged uneventfully.

those who were immunocompromised. Although there was no statistical significance, the immunocompromised cohort showed a larger extent of total disease and consolidation than the immunocompetent group. Multifocal pneumonia pattern was more frequently found in immunocompromised patients than in immunocompetent patients. Similarly, a previous study about influenza viral pneumonia reported that the interstitial-parenchymal pattern (bilateral GGO and consolidation and/or interlobular septal thickening) was more frequently found in immunocompromised patients (28).

This study has several limitations. First, quantitative $\mathrm{HBoV}$ viral loads from patient respiratory secretions were not available in our study. Such measures can indicate disease severity as shown in a previous study, in which high viral load was a significant predictor of severe pneumonia in children (22). However, we did not routinely obtain viral loads for HBoV infection in our hospital. Second, we only evaluated $\mathrm{CT}$ finding of $\mathrm{HBoV}$ pneumonia without coinfection; therefore, the number of patients included for imaging analysis was small. However, this study involves the largest population of a rare incidence of $\mathrm{HBoV}$ pneumonia in adults. Last, not all patients with HBoV pneumonia underwent chest CT. Moreover, BAL procedure was not performed for all patients. Therefore, the incidence of mild pneumonia, which can be detected on CT scan or BAL, may be underestimated.

In conclusion, $\mathrm{HBoV}$ infection can cause respiratory infection in adults and is associated with a high incidence of pneumonia, especially in older patients and patients with nosocomial infection. The HBoV pneumonia can be included as one of the differential diagnosis in adult patients, whether immunocompromised or immunocompetent, 
especially when multifocal areas of consolidation and/ or GGO are seen on chest CT. Early CT diagnosis may allow timely initiation of effective treatment.

\section{Supplementary Materials}

The Data Supplement is available with this article at https://doi.org/10.3348/kjr.2018.0634.

\section{Conflicts of Interest}

The authors have no potential conflicts of interest to disclose.

\section{ORCID iDs}

Kyung-Hyun Do

https://orcid.org/0000-0003-1922-4680

Han Na Lee

https://orcid.org/0000-0002-1570-0603

Hyun Jung Koo

https://orcid.org/0000-0001-5640-3835

Soo Hyun Kim

https://orcid.org/0000-0002-1993-479X

Sang Ho Choi

https://orcid.org/0000-0002-4972-4531

Heungsup Sung

https://orcid.org/0000-0002-6062-4451

\section{REFERENCES}

1. Allander T. Human bocavirus. J Clin Virol 2008;41:29-33

2. Brieu N, Guyon G, Rodière M, Segondy M, Foulongne V. Human bocavirus infection in children with respiratory tract disease. Pediatr Infect Dis J 2008;27:969-973

3. Fry AM, Lu X, Chittaganpitch M, Peret T, Fischer J, Dowell SF, et al. Human bocavirus: a novel parvovirus epidemiologically associated with pneumonia requiring hospitalization in Thailand. J Infect Dis 2007;195:1038-1045

4. Pozo F, García-García ML, Calvo C, Cuesta I, Pérez-Breña P, Casas I. High incidence of human bocavirus infection in children in Spain. J Clin Virol 2007;40:224-228

5. Zheng LS, Yuan XH, Xie ZP, Jin Y, Gao HC, Song JR, et al. Human bocavirus infection in young children with acute respiratory tract infection in Lanzhou, China. J Med Virol 2010;82:282-288

6. Allander T, Tammi MT, Eriksson M, Bjerkner A, TiveljungLindell A, Andersson B. Cloning of a human parvovirus by molecular screening of respiratory tract samples. Proc Natl Acad Sci U S A 2005;102:12891-12896

7. Koo HJ, Lim S, Choe J, Choi SH, Sung H, Do KH. Radiographic and CT features of viral pneumonia. Radiographics 2018;38:719-739

8. Calvo C, García-García ML, Pozo F, Carballo D, MartínezMonteserín $\mathrm{E}$, Casas I. Infections and coinfections by respiratory human bocavirus during eight seasons in hospitalized children. J Med Virol 2016;88:2052-2058

9. Maggi F, Andreoli E, Pifferi M, Meschi S, Rocchi J, Bendinelli M. Human bocavirus in Italian patients with respiratory diseases. J Clin Virol 2007;38:321-325

10. Allander T, Jartti T, Gupta S, Niesters HG, Lehtinen P, Osterback $\mathrm{R}$, et al. Human bocavirus and acute wheezing in children. Clin Infect Dis 2007;44:904-910

11. Garbino J, Soccal PM, Aubert JD, Rochat T, Meylan P, Thomas $Y$, et al. Respiratory viruses in bronchoalveolar lavage: a hospital-based cohort study in adults. Thorax 2009;64:399404

12. Gu K, Van Caeseele P, Dust K, Ho J. Atypical pneumonia due to human bocavirus in an immunocompromised patient. CMAJ 2017;189:E697-E699

13. Kupfer B, Vehreschild J, Cornely 0, Kaiser R, Plum G, Viazov S, et al. Severe pneumonia and human bocavirus in adult. Emerg Infect Dis 2006;12:1614-1616

14. Liu WK, Chen DH, Liu Q, Liang HX, Yang ZF, Qin S, et al. Detection of human bocavirus from children and adults with acute respiratory tract illness in Guangzhou, southern China. BMC Infect Dis 2011;11:345

15. Herbst T, Van Deerlin VM, Miller WT Jr. The CT appearance of lower respiratory infection due to parainfluenza virus in adults. AJR Am J Roentgenol 2013;201:550-554

16. Micek ST, Kollef KE, Reichley RM, Roubinian N, Kollef MH. Health care-associated pneumonia and community-acquired pneumonia: a single-center experience. Antimicrob Agents Chemother 2007;51:3568-3573

17. El Chaer F, Shah DP, Kmeid J, Ariza-Heredia EJ, Hosing CM, Mulanovich VE, et al. Burden of human metapneumovirus infections in patients with cancer: risk factors and outcomes. Cancer 2017;123:2329-2337

18. Su YB, Sohn S, Krown SE, Livingston PO, Wolchok JD, Quinn $C$, et al. Selective CD4+ lymphopenia in melanoma patients treated with temozolomide: a toxicity with therapeutic implications. J Clin Oncol 2004;22:610-616

19. Hansell DM, Bankier AA, MacMahon H, McLoud TC, Müller NL, Remy J. Fleischner Society: glossary of terms for thoracic imaging. Radiology 2008;246:697-722

20. Lichtenberger JP 3rd, Sharma A, Zachary KC, Krishnam MS, Greene RE, Shepard JA, et al. What a differential a virus makes: a practical approach to thoracic imaging findings in the context of HIV infection--part 1, pulmonary findings. AJR Am J Roentgenol 2012;198:1295-1304

21. Miller WT Jr, Mickus TJ, Barbosa E Jr, Mullin C, Van Deerlin VM, Shiley KT. CT of viral lower respiratory tract infections in adults: comparison among viral organisms and between viral and bacterial infections. AJR Am J Roentgenol 2011;197:10881095 
22. Jiang W, Yin F, Zhou W, Yan Y, Ji W. Clinical significance of different virus load of human bocavirus in patients with lower respiratory tract infection. Sci Rep 2016;6:20246

23. MacFadden DR, LaDelfa A, Leen J, Gold WL, Daneman N, Weber $E$, et al. Impact of reported beta-lactam allergy on inpatient outcomes: a multicenter prospective cohort study. Clin Infect Dis 2016;63:904-910

24. Walsh EE, Peterson DR, Falsey AR. Human metapneumovirus infections in adults: another piece of the puzzle. Arch Intern Med 2008;168:2489-2496

25. Koo HJ, Lee HN, Choi SH, Sung H, Oh SY, Shin SY, et al. Human metapneumovirus infection: pneumonia risk factors in patients with solid organ transplantation and computed tomography findings. Transplantation 2018;102:699-706

26. Kim EA, Lee KS, Primack SL, Yoon HK, Byun HS, Kim TS, et al. Viral pneumonias in adults: radiologic and pathologic findings. Radiographics 2002;22 Spec No:S137-S149

27. Chong S, Lee KS, Kim TS, Chung MJ, Chung MP, Han J. Adenovirus pneumonia in adults: radiographic and highresolution CT findings in five patients. AJR Am J Roentgenol 2006;186:1288-1293

28. Kloth C, Forler S, Gatidis S, Beck R, Spira D, Nikolaou K, et al. Comparison of chest-CT findings of influenza virus-associated pneumonia in immunocompetent vs. immunocompromised patients. Eur J Radiol 2015;84:1177-1183 